\title{
Basic Fibroblast Growth Factor (Fgf2) Is Necessary for Cell Proliferation and Neurogenesis in the Developing Cerebral Cortex
}

\author{
Rossana Raballo, ${ }^{1}$ Julianne Rhee, ${ }^{1}$ Richard Lyn-Cook, ${ }^{1}$ James F. Leckman, ${ }^{1}$ Michael L. Schwartz, ${ }^{2}$ and \\ Flora M. Vaccarino ${ }^{1,2}$ \\ ${ }^{1}$ Child Study Center and 2Section of Neurobiology, Yale University, New Haven, Connecticut 06520
}

Little is known about regionally specific signals that control the number of neuronal progenitor cells in vivo. We have previously shown that the germline mutation of the basic fibroblast growth factor (Fgf2) gene results in a reduction in the number of cortical neurons in the adult. We show here that Fgf2 is expressed in the pseudostratified ventricular epithelium (PVE) in a dorsoventral gradient and that Fgf2 and its receptor, Fgfr-1, are downregulated by mid to late stages of neurogenesis. In Fgf2 knockout mice, the volume and cell number of the dorsal PVE (the cerebral cortical anlage) are substantially smaller, whereas the volume of the basal PVE is unchanged. The dorsal PVE of Fgf2 knockout mice has a $50 \%$ decrease in founder cells and a reduced expansion of the progenitor pool over the first portion of neurogenesis. Despite this reduction, the degree of apoptosis within the PVE is not changed in the Fgf2 knockouts. Cortical neuron number was decreased by $45 \%$ in Fgf2 knockout mice by the end of neurogenesis, whereas the number of neurons in the basal ganglia was unaffected. Microscopically, the frontal cerebral cortex of neonatal Fgf2 null mutant mice lacked large neurons in deep cortical layers. We suggest that Fgf2 is required for the generation of a specific class of cortical neurons arising from the dorsal PVE.

Key words: fibroblast growth factor; Fgf2; knockout; null mutation; gene; neurogenesis; mouse; pseudostratified ventricular epithelium; apoptosis; cell division; neuronal progenitor; cerebral cortex; basal ganglia
The CNS of vertebrates originates from neuroepithelial cells located within the embryonic neural tube. Progenitor cells located within the pseudostratified ventricular epithelium (PVE) lining the dorsal portion of the telencephalic vesicles give rise to the cerebral cortex, whereas cells within the basal PVE give rise to the basal ganglia. In rodents, cortical neurogenesis lasts $\sim 7 \mathrm{~d}$, from embryonic day 11.5 (E11.5) to E17.5 in mouse and from E13.5 to E19.5 in rat (Bayer and Altman, 1991; Caviness et al., 1995; Takahashi et al., 1995).

Several mitogenic and trophic factors have been implicated in the processes of cortical cell proliferation and differentiation. These include fibroblast growth factor (Fgf), insulin growth factor (Igf), and epidermal growth factor (Egf). For example, Fgf, Egf, and Igf all promote neurogenesis when added to cultures of precursor cells from hippocampus, forebrain, cerebellum, and spinal cord (Gensburger et al., 1987; Drago et al., 1991; Ray et al., 1993; Vescovi et al., 1993; Ray and Gage, 1994; Vaccarino et al., 1995; Kalyani et al., 1997). Fgf2 and Egf also promote the proliferation of stem cells isolated from the adult brain and may direct them toward specific fates (Craig et al., 1996; Kuhn et al., 1997). Mice lacking the Egf receptor develop a progressive neuronal degeneration in various brain regions beginning at postnatal day 4 (P4), possibly because of a lack of trophic support from glial cells in the postnatal period (Sibilia and Wagner, 1995; Sibilia et al., 1998). In contrast, analyses of mutant mice lacking specific Fgf

\footnotetext{
Received Dec. 14, 1999; revised March 29, 2000; accepted April 11, 2000.

This work has been supported by the National Science Foundation (IBN-9514283) and National Institutes of Health (Public Health Service Grants R01NS37709, P01NS22087, and P01NS35476). We thank Drs. Verne Caviness, Richard Nowakowski, John Rubenstein, Janice Naegele, and Paul Lombroso for their helpful comments on this manuscript.

Correspondence should be addressed to Dr. Flora M. Vaccarino, Child Study Center, Yale University, 230 South Frontage Road, New Haven, CT 06520. E-mail: flora.vaccarino@yale.edu.

Copyright (C) 2000 Society for Neuroscience $\quad 0270-6474 / 00 / 205012-12 \$ 15.00 / 0$
}

ligands and receptors (Fgfrs) demonstrate that Fgf family members are required for the morphogenesis of derivatives of the neural folds and neural tube during embryonic development. Fgf ligands and Fgfrs are expressed by neural progenitor cells from the earliest phases of morphogenesis (Ernfors et al., 1990; Gonzalez et al., 1990; Giordano et al., 1991; Powell et al., 1991; Nurcombe et al., 1993; Weise et al., 1993). Fgfr-1 and Fgfr-2 are likely to be involved in early CNS pattern formation, whereas Fgfr-3 and Fgfr-4 are not essential for embryonic development (Yamaguchi et al., 1994; Deng et al., 1996; Partanen et al., 1998; Weinstein et al., 1998; Tropepe et al., 1999). Fgf8 regulates growth and patterning of the midbrain and the anterior forebrain, and Fgf3 is essential for the formation of the inner ear (Represa et al., 1991; Crossley et al., 1996; Shimamura and Rubenstein, 1997; Martinez et al., 1999). We and others have shown that Fgf2 regulates neuronal density (Dono et al., 1998; Ortega et al., 1998) and number (Vaccarino et al., 1999a) in the cerebral cortex. In mice homozygous for a Fgf2 null allele, the number of cortical neurons is decreased by $50 \%$ with respect to wild-type mice (Vaccarino et al., 1999a). The biological mechanism responsible for this defect remains unclear. It may reflect a role for Fgf2 in regulating the genesis of neuronal cells, their correct targeting to the cortical plate, or cell survival. Fgf2 promotes neuronal survival in vitro (Walicke, 1988) and is expressed by cortical astrocytes, which provide trophic support to neuronal cells (Woodward et al., 1992). However, whether endogenous Fgf2 is essential for the survival of cortical neurons in vivo is unknown.

We have shown previously that the microinjection of recombinant Fgf2 protein into the cerebral ventricles of rat embryos increases the generation of cortical neurons and the percentage of proliferating cells within the PVE (Vaccarino et al., 1999a). These data suggest that Fgf2 is sufficient to promote the division of cortical progenitor cells. In the present work we investigate whether endogenous Fgf2 is necessary for the proper growth of 
the telencephalic neuroepithelium during embryonic development. We generated estimates for volume and number of progenitors within dorsal and basal PVE in wild-type and Fgf2-/mice. We found that the dorsal PVE is severely depleted of progenitor cells in Fgf2 knockout embryos from the beginning of corticogenesis. The growth dynamics of the dorsal PVE were further analyzed by assessing the number of dividing cells accumulating within this region during the first portion of neurogenesis. Ongoing cell death was determined in control and mutant mice to ascertain the role of Fgf2 in cell survival. To determine whether altered growth dynamics of the dorsal PVE cause a defect in neurogenesis in mice lacking Fgf2, we estimated cortical neuron number at birth in Fgf2 knockout mice and wild-type littermates.

Although cortical pyramidal neurons arise from the dorsal PVE, a major portion of cortical GABAergic interneurons are generated in the basal PVE and subsequently migrate to the developing cortical plate (de Carlos et al., 1996; Anderson et al., 1997b; Pearlman, 1998; Tan et al., 1998; Lavdas et al., 1999). To investigate whether Fgf2 is required for the development of the basal ganglia, we assessed the volume of the lateral and medial eminences within the basal PVE and the number of neurons within the basal ganglia at birth in mutant and wild-type mice. Our results strongly suggest that Fgf2 controls the growth of the dorsal but not of the basal telencephalon. Thus, one role of Fgf2 during normal development may be to amplify the progenitor pool for pyramidal projection neurons without affecting cortical interneurons.

\section{MATERIALS AND METHODS}

Animals. A colony of Fgf2 wild-type and knockout mice (in a 129Sv: Black Swiss genetic background) was established from the original colony (Zhou et al., 1998) using two heterozygous mating pairs (Fgf $2+/-$ ). The colony was maintained by crosses between heterozygous parents to minimize genetic background effects. Most of the embryos that were used for this study were the progeny of heterozygous parents, which in turn were progeny of heterozygous parents as well. Mice were genotyped by PCR using primers specific for the wild-type and the Fgf2 knockout allele (Zhou et al., 1998). The day of the plug was assumed to be E0.5, and the day of birth was denoted as P1.

Immunocytochemistry. Immunostaining for Fgf2 was characterized in embryonic tissue by varying fixation conditions and tissue processing using an anti-rat Fgf2 antiserum raised against the 12 amino terminal amino acids of the rat Fgf2 molecule (Gonzalez et al., 1995). This antiserum recognizes all three molecular weight forms of Fgf2 in the rat brain (data not shown). For the immunodetection of Fgfr-1 we used a polyclonal antiserum binding to the Fgfr-1 intracellular domain (Santa Cruz) and a polyclonal antiserum recognizing the extracellular domain of Fgfr-1/splice variant IIIc (Ab 15, gift of T. Williams, Chiron Corp., Emeryville, CA). Results obtained using these antibodies were similar. Immunocytochemistry was performed in $20-\mu$ m-thick rat brain cryostat sections using an avidin-biotin peroxidase complex (ABC Vectastain Elite, Vector Laboratories, Burlingame, CA) and diaminobenzidine (DAB) as substrate, as described previously (Vaccarino et al., 1999a).

NeuN immunostaining was performed using a commercially available monoclonal antibody (Chemicon, Temecula, CA). Mice were perfused intracardially with $4 \%$ paraformaldehyde, and their brains were embedded in paraffin. Immunocytochemistry was performed using every 10th section in series of $10-\mu$ m-thick sections encompassing the entire brain. Sections were deparaffinized and subjected to an antigen retrieval procedure (Antigen unmasking solution, Vector) at $80^{\circ} \mathrm{C}$ for $1 \mathrm{hr}$.

Estimation of volume and cell number. The volume and number of cresyl violet-, BrdU-, or NeuN-stained cells were determined by unbiased stereological methods as described (Gundersen et al., 1988; West et al., 1991; Vaccarino et al., 1999a). To label all proliferating cells within the PVE, timed-pregnant females from heterozygous (Fgf $2+/-)$ matings were injected with $\mathrm{BrdU}(50 \mu \mathrm{g} / \mathrm{g}$, i.p.) every $3 \mathrm{hr}$ to ensure that all cells passing through S-phase would be labeled. Embryos were harvested at a time $t \gg T c-T s$ from the beginning of labeling, equal to $6.6-8 \mathrm{hr}$ for
E10.5-E12.5 embryos based on previously obtained cell cycle parameters (Takahashi et al., 1995; Vaccarino et al., 1999a). By the time of harvesting, all dividing cells have incorporated $\mathrm{BrdU}$, and the proportion of BrdU-labeled cells corresponds to the growth fraction. Embryos were staged (Brown, 1990) and genotyped by PCR, and the homozygous Fgf $2+/+$ and Fgf2 $-/-$ embryos were analyzed. Embryos were fixed in $70 \%$ ethanol $/ 5 \%$ acetic acid and embedded in paraffin. Sections $(10 \mu \mathrm{m}$ thick) were immunostained with an anti-BrdU antibody (Amersham, Arlington Heights, IL) after preincubation with $2 \mathrm{~N} \mathrm{HCl}$ and counterstained with cresyl violet as described (Vaccarino et al., 1999a).

The cortical plate and PVE reference volumes were determined by the Cavalieri method. The borders of the cerebral cortex were drawn at a magnification of $23 \times$ based on cytoarchitectonic features as follows: inferiorly, the subplate; anteriorly, the pyriform cortex; and posteriorly, the subiculum (these cortical areas were not included in the analyses). The borders of the PVE were drawn based on BrdU-stained areas in the telencephalon at a magnification of $70 \times$. The boundaries of the dorsal PVE were as follows: anteriorly, the septal eminence; laterally, the lateral ganglionic eminence; and caudally, the amygdaloid epithelium. The borders of the basal PVE (comprising the lateral and medial ganglionic eminence) were as follows: caudally, the diencephalon (thalamus and hypothalamus); rostrally, the dorsal PVE; and medially, the strionuclear epithelium. These limits were reliably assessed by at least two independent investigators. A grid point counting method was used to determine surface area; section thickness was measured with a stage micrometer (Vaccarino et al., 1999a). The volume was calculated by the formula $V=\Sigma P^{*} a(p)^{*} t$, where $a(p)$ is the area between grid points (corrected for magnification), $\Sigma P$ is the number of points intersecting the neuroepithelium, and $t$ is the thickness of the sample measured.

The total number of cells was estimated by the optical disector method (West, 1993). In each section in the series, cell nuclei were counted in three-dimensional counting frames $(40 \times 30 \times 4 \mu \mathrm{m})$ systematically sampled throughout the area of interest. Cells that intersected the lowermost focal (exclusion) plane and those that intersected the exclusion boundaries of the unbiased sampling frame were excluded from counting. The mean cell number per disector volume was multiplied by the reference volume, yielding an estimate for total number of cells. The proportion of nondividing cells detected in our wild-type mice $(\sim 10 \%$; see Table 3$)$ is higher than that reported in the literature $(\sim 1-7 \%$, depending on the number of bins included in the analysis and fixation conditions) (Takahashi et al., 1993; Haydar et al., 2000). This difference could be accounted for by strain differences, nuclear access to BrdU, or different affinity of our BrdU antibody.

Detection of apoptotic cells. We used terminal deoxytransferase (TdT) to end-label DNA fragments within the nuclei of apoptotic cells [terminal deoxynucleotidyl transferase-mediated biotinylated dUTP nick end labeling (TUNEL) procedure] (Gavrieli et al., 1992) with the following modifications. Mouse embryos were fixed in $70 \%$ ethanol $/ 5 \%$ acetic acid and embedded in paraffin. Dewaxed and rehydrated $10 \mu \mathrm{m}$ tissue sections from the same animals used in stereological studies were treated with $0.6 \%$ Triton $\mathrm{X}-100$, heated at $85^{\circ} \mathrm{C}$ for $1 \mathrm{hr}$ in Antigen Unmasking Solution (Vector), and then immersed for $5 \mathrm{~min}$ in a $0.6 \% \mathrm{H}_{2} \mathrm{O}_{2}$ solution to inactivate endogenous peroxidase activity. Sections were preincubated for $15 \mathrm{~min}$ in terminal transferase buffer $(150 \mathrm{~mm}$ sodium cacodylate, 25 $\mathrm{mm}$ Tris- $\mathrm{HCl}, 0.25 \mathrm{mg} / \mathrm{ml} \mathrm{BSA}$, and $\left.1.5 \mathrm{~mm} \mathrm{CoCl}_{2}, \mathrm{pH} 7.4\right)$ at $37^{\circ} \mathrm{C}$ and then incubated with terminal transferase $(0.15 \mathrm{U} / \mu \mathrm{l}), 10 \mu \mathrm{M}$ dATP, 2.5 $\mu \mathrm{M}$ biotin-16-dUTP in the same buffer for $2 \mathrm{hr}$ at $37^{\circ} \mathrm{C}$. After three washes in PBS, sections were incubated for $1 \mathrm{hr}$ with biotinylated peroxidase-avidin complex (ABC) (Vectastain Elite, Vector), and the peroxidase activity was then visualized by the precipitation of $0.03 \%$ DAB in the presence of $0.01 \% \mathrm{H}_{2} \mathrm{O}_{2}$ in PBS. Finally, sections were counterstained with methyl green, dehydrated in alcohol, and mounted with Permount. Sections preincubated with $0.1 \mathrm{mg} / \mathrm{ml}$ DNase I, in which all cells were stained, were used as positive controls. Apoptotic cells were invariably visualized within the epidermis, within the endothelium of the tongue, and at the tips of the turbinates within the nasal cavity and were used as internal positive controls (see Fig. 5).

\section{RESULTS}

\section{Dynamics of Fgf2 and Fgfr-1 expression in the developing cerebral cortical wall}

In the rat cerebrum, E14.5/E15.5 corresponds to the period when neurons of layers 5 and 6 of the cerebral cortex are generated (Bayer and Altman, 1991). Fgf2-like immunoreactivity was ex- 


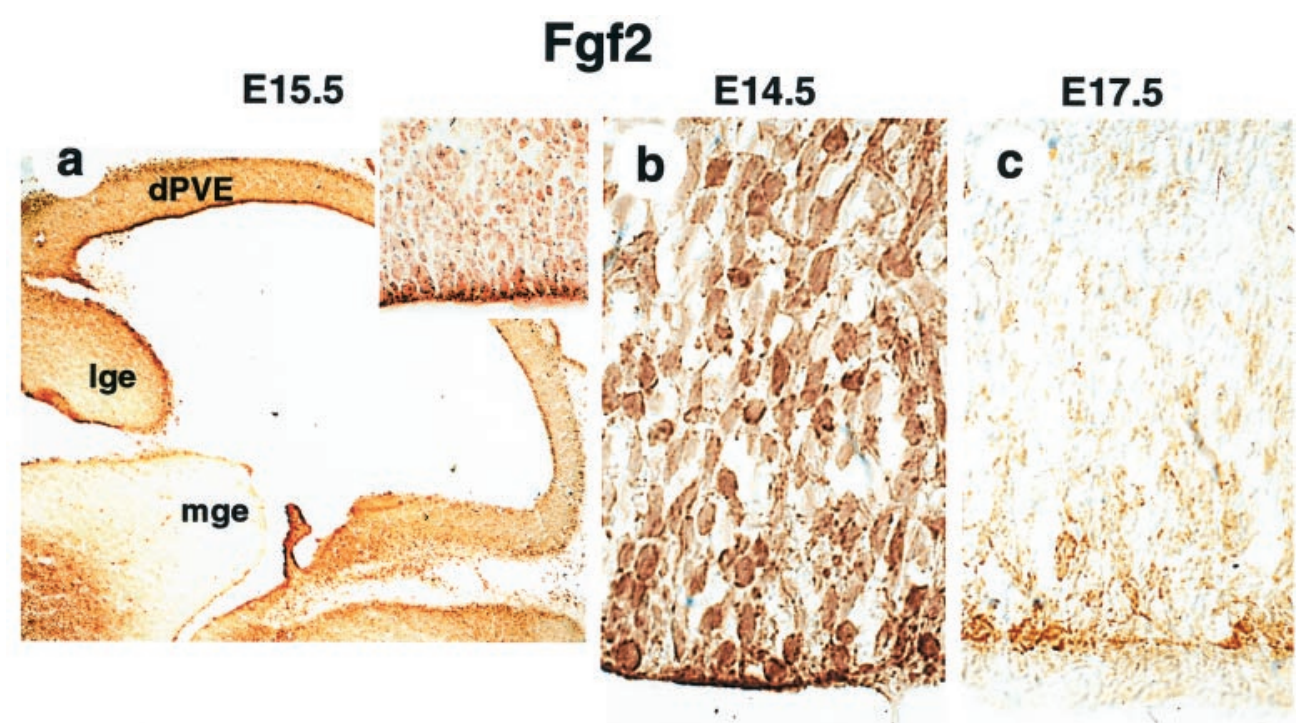

Fgfr-1

E14.5

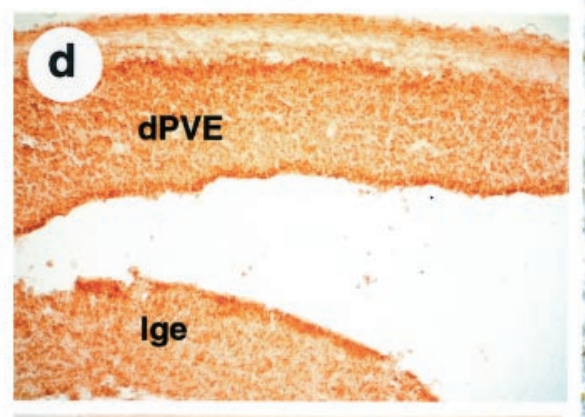

reaction is present after preincubation of the Fgfr-1 antibody with an excess of Fgfr-1 peptide. $h$ shows BrdU immunostaining (green) after BrdU incorporation in vivo for $3.5 \mathrm{hr}$, and $i$ shows the same section double-immunostained with Fgfr-1. Arrows indicate proliferative cells that contain Fgfr-1 immunoreactivity. In $a, d$, and $g$, anterior is left, and in all sections the ventricular surface is at the bottom. lge, Lateral ganglionic eminence; mge, medial ganglionic eminence; $d P V E$, dorsal PVE. Scale bars: $a, 400 \mu \mathrm{m} ; d, g, 200 \mu \mathrm{m} ; b, c, e, f, 20$ $\mu \mathrm{m} ; h, i, 50 \mu \mathrm{m}$.

pressed throughout the telencephalon at these stages, particularly in the PVE, the marginal layer, and the ectoderm (Fig. 1a). In the PVE, Fgf2 expression was strongest in rostral and dorsal regions and reached the lowest levels in the medial ganglionic eminence (Fig. 1a).

Many neuroepithelial cells of the dorsal portion of the PVE displayed both nuclear and cytoplasmic Fgf2-like immunoreactivity at E14.5 (corresponding to E12.5 in mouse) (Fig. 1b). Fgf2 immunoreactivity was decreased within the thickness of the PVE $1 \mathrm{~d}$ later but maintained in the apical portion (Fig. 1a, inset). By E17.5, Fgf2-like immunoreactivity disappeared from the entire neuroepithelium, except for scattered apical cells (Fig. 1c). Previously, we reported a similar downregulation for Fgf2 mRNA levels (Vaccarino et al., 1999a). Conversely, Fgf2 was strongly expressed at E17.5 in superficial tissues, the meninges, and the choroid plexus (Fig. 1 and data not shown). We could not detect

\section{E14.5}

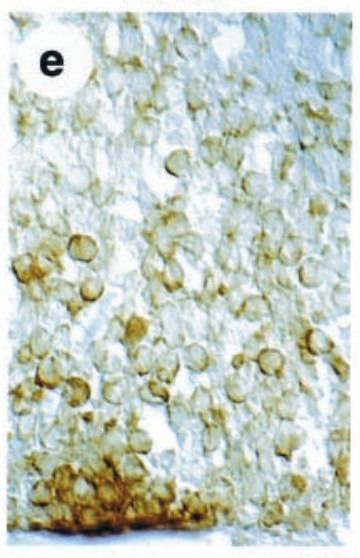

E17.5

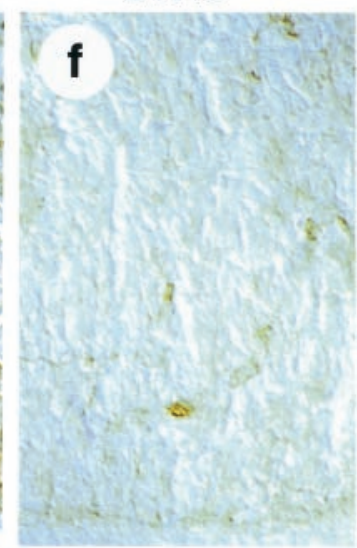

E15.5

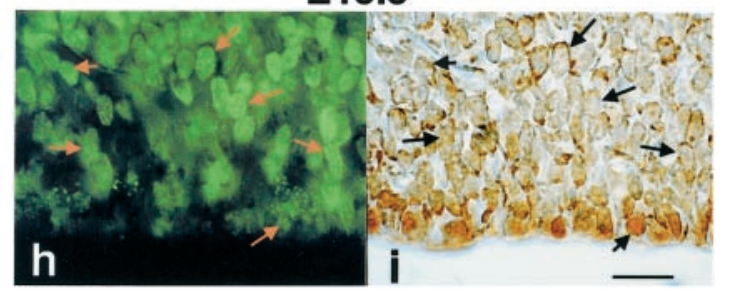

the Fgf2 protein above background levels in either the cortical plate or within migrating neurons in the intermediate zone (IZ). Subsequently, postmitotic cortical neurons upregulated Fgf2 expression in the postnatal period (data not shown) (Kuzis et al., 1995).

We compared Fgf2 expression with that of Fgfr-1 at these phases of cortical development. The pattern of Fgfr-1 immunoreactivity was similar using different anti-Fgfr-1 antisera, and this staining was abolished after preabsorption of the Fgfr-1 antiserum with the Fgfr-1 peptide (Fig. $1 d, g$ ). At E14.5 in the rat telencephalon, Fgfr-1 immunoreactivity was expressed throughout the dorsal and basal portions of the PVE (Fig. 1d). A similar generalized pattern of expression was observed in the mouse telencephalon at E11.5 and E12.5 (data not shown). At higher magnification, Fgfr-1 was strongly expressed throughout the thickness of the PVE, but similar to Fgf2, it was strongest in 
dorsal PVE

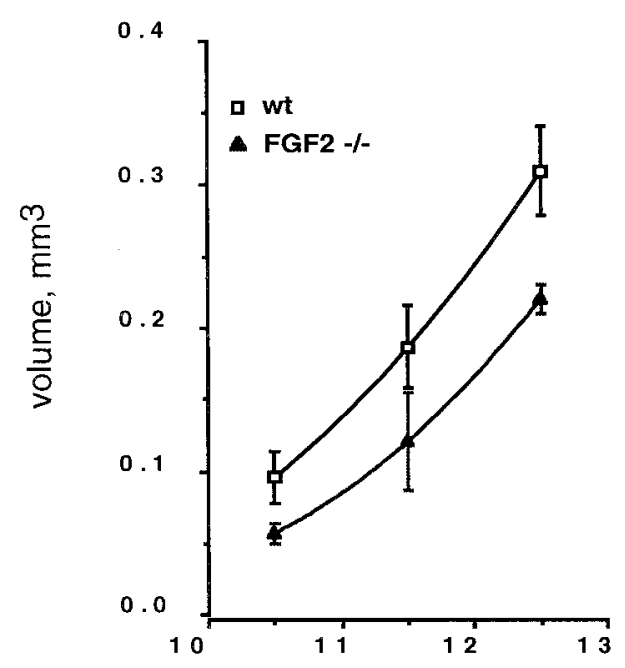

\section{basal PVE}

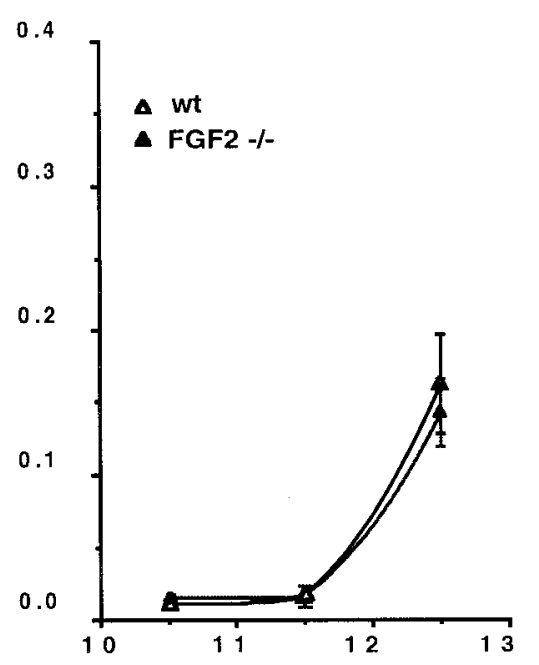

embryonic days
Figure 2. Decrease in PVE size in Fgf2- $/-$ mice. Estimation of dorsal and basal PVE volumes for Fgf2-/- mutant and wild-type littermate mice. Embryos were harvested at the indicated stages after the entire proliferative population was labeled with cumulative BrdU injections. Volumes were determined by the Cavalieri method using serial sections immunostained for BrdU and counterstained with cresyl violet. apical cells and in the neuroepithelial end feet (Fig. 1d,e,i and data not shown). Fgfr-1 was downregulated during development in a pattern strikingly similar to that of Fgf2. By E17.5, Fgfr-1-like immunoreactivity was essentially absent from the entire neuroepithelium except for scattered cells (Fig. 1f). By this stage and continuing postnatally, Fgfr-1 was expressed by neurons within the cortical plate.

To investigate whether Fgfr-1 was expressed by proliferative or postmitotic cells of the germinal neuroepithelium, dividing cells were labeled with 2-bromodeoxyurdine (BrdU) in vivo. After 3.5 hr of cumulative labeling, when BrdU-incorporating cells are between S and early G1 phases (Reznikov and van der Kooy, 1995), embryos were killed, and brain sections were doubleimmunostained for BrdU and Fgfr-1. Fgfr-1 immunoreactivity was colocalized with BrdU in many proliferating cells of the PVE (Fig. 1h,i). Thus, proliferating cells of both dorsal and basal PVE express the Fgfr-1 gene product, suggesting that these cells should respond directly to ligands of the Fgf family.

\section{The volume of the dorsal PVE of Fgf2-/- mice is decreased from early stages of neurogenesis}

To understand the role that Fgf2 may play during neurogenesis, we studied the Fgf2 knockout mouse. From E10.5 through E14.5 in mouse, the PVE can be identified using cumulative BrdU incorporation. The PVE occupies nearly the entire width of the cerebral wall at these early stages of neurogenesis. By E14.5, the secondary proliferative population (SPP), which is thought to be composed mainly of glial progenitor cells, has not yet emerged (Takahashi et al., 1995). During this period, progenitor cells undergo a nearly exponential expansion (Takahashi et al., 1996), reflected by an increase in the volume of both the basal and dorsal portions of the PVE (Fig. 2). In Fgf2 knockout mice, the volume of the dorsal PVE was smaller compared with wild-type mice, and the rate of increase in volume of the dorsal PVE was slower over the initial stages of neurogenesis (Fig. 2). There was a significant effect of genotype on volume across the ages examined (E10.5E12.5) $(\mathrm{F}=13.5 ; p<0.01$, ANOVA). Conversely, the volume of the basal PVE did not differ between Fgf2 null mutant and wild-type mice $(\mathrm{F}=0.17 ; p=0.68)$ (Fig. 2). These data suggest that Fgf2 may be necessary for the normal morphogenesis of the dorsal but not the basal telencephalon.

Interestingly, the impact of the Fgf2 gene mutation on the volume of the dorsal PVE was greatest at the earliest time point examined. The dorsal PVE of Fgf2 knockout embryos was 41, 35, and $29 \%$ smaller at E10.5, E11.5, and E12.5, respectively, as compared with wild-type mice (Fig. 2).

\section{Fgf2 regulates cell division within the dorsal PVE}

A possible mechanism for the early decrease in PVE volume is that the lack of Fgf2 affects the size of the founder population at the start of cortical neurogenesis. For example, Fgf2 may act on the mechanisms that allocate progenitor cells to distinct fates. Alternatively, Fgf2 may regulate cell division within the dorsal telencephalic neuroepithelium. To investigate these possibilities, we first determined whether the decrease in volume of the dorsal PVE in Fgf2 null mutant mice was caused by a change in cell number. Second, we estimated the number and density of both dividing and nondividing cells within the dorsal PVE of Fgf2-/and Fgf $2+/+$ mice. If the main action of Fgf2 is to regulate the allocation of cell fates within the telencephalon, we expected no change in the proportion of proliferating cells in Fgf2 null mutant mice.

Wild-type mice had a total of $6.88 \pm 1.45 \times 10^{5}$ cells in the dorsal PVE at the beginning of neurogenesis (E10.5). In contrast, Fgf2 null mutant mice began neurogenesis with only $3.08 \pm$ $0.42 \times 10^{5}$ cells in the dorsal PVE, $\sim 50 \%$ fewer cells than in wild-type mice (see Fig. 4). The overall effect of genotype on cell number was highly significant $(\mathrm{F}=6.7 ; p<0.01)$. For both wild-type and mutant mice, the initial cell number increased nearly exponentially over the first $24 \mathrm{hr}$ of neurogenesis, consistent with an initial duration of the cell cycle of $\sim 8 \mathrm{hr}$ (Takahashi et al., 1995) (Fig. 3). However, the slope of the curve describing the rate of increase in cell number was $889 \times 10^{5}$ cells per day for wild-type embryos and $630 \times 10^{5}$ cells per day for Fgf2 null mutant embryos. This difference suggests that the initial rate of increase in cell number within the PVE is slower in mutant 


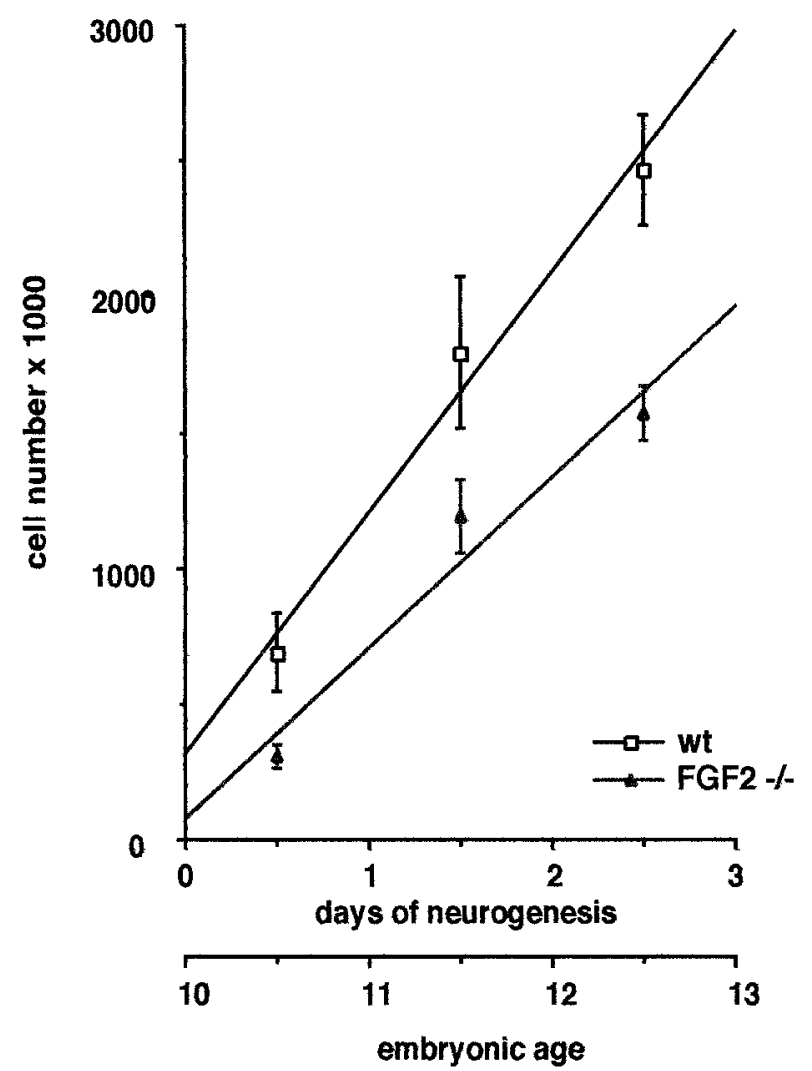

Figure 3. The rate of increase in cell number within the PVE is lower in Fgf2 knockout embryos. Shown is a plot of cell number as a function of age in the dorsal portion of the PVE during the initial stages of neurogenesis. Cell number was assessed by stereological analyses in Fgf2 null mutant $(F g f 2-/-)$ and wild-type $(w t)$ littermates. Curve fitting yielded the equations $y=317+888 \cdot x$ for wild type and $y=78+630 \cdot x$ for Fgf $2-/-; R^{2}$ was 0.98 and 0.95 , respectively. Cell number was significantly different between genotypes by ANOVA $(\mathrm{F}=6.7 ; p<0.01)$.

embryos lacking Fgf2. Thus, in the neuroepithelium of Fgf2 knockout embryos, not only is the initial number of cells smaller, but there is a reduced amplification of neuroepithelial cell number during the first phase of neurogenesis.

To determine whether cell proliferation is altered by the absence of Fgf2, we performed a separate analysis for proliferating and nonproliferating cells within the PVE of control and mutant mice. Both the density (Table 1 ) and number (Table 2 ) of proliferating cells were consistently decreased in Fgf2 mutant mice. The most dramatic change was observed at E10.5, when proliferating cells of the dorsal PVE showed a $60 \%$ decrease in number for Fgf2-/- mice compared with wild-type embryos. Proliferating cells decreased by 45 and $40 \%$, respectively, at E11.5 and E12.5 in Fgf2 null mutants compared with wild-type mice (Table 2).

Conversely, nonproliferating cells within the PVE were not consistently changed in Fgf2 knockout mice. The density of nonproliferating cells was significantly increased in Fgf2 null mutants, whereas their number was not significantly affected (Tables 1, 2). By ANOVA, there was a significant interaction between the effect of genotype and cell type (proliferating/nonproliferating) (see legends of Tables 1 and 2). The main effect of genotype on cell number was entirely attributable to an effect on proliferating cells. As a result of these changes, the proportion of proliferating cells, or the growth fraction, was decreased in Fgf2 knockouts. For asynchronously dividing cells such as the PVE, the growth fraction is calculated by assessing the proportion of cells incorporating BrdU after a suitable labeling period $(t \gg$ $T c-T s)$. As summarized in Table 3, the growth fraction was decreased for E10.5 and E11.5, whereas it was not changed for E12.5 and E15.5 in null mutant animals versus wild-type mice.

In summary, our results show that the absence of Fgf2 lowers the number of cell divisions within the cortical neuroepithelium. This is attributable to a lower pool of cortical progenitors, which affects the size of the dorsal telencephalon, and to an alteration in their proliferation. These changes alter the course of early cortical neurogenesis.

\section{Regionally specific neurogenetic defects in Fgf2 knockout mice}

To find out whether the decrease in the proliferative pool produces a defect in the total neuronal output of the PVE, we estimated the number of neurons at the end of neurogenesis in both the cortex and striatum. Mice were analyzed between P1 and P3, a time at which neurons have completed their migration to the cortical plate. Neurons were identified by immunostaining with $\mathrm{NeuN}$, one of the earliest markers for terminally differentiated neurons. In wild-type mice, the total number of NeuN-positive neurons in the cerebral cortex at birth was 14.25 million per hemisphere (Table 4), as compared with 7.07 million per hemisphere in the adult (Vaccarino et al., 1999a). Thus, the number of cortical neurons, phenotypically identified using NeuN, was twice as great at P1 than at maturity. These data allow us to estimate that normally $50 \%$ of cortical neurons will die during the major phase of programmed cell death in the early postnatal period.

The number of cortical neurons in Fgf2 null mutant mice at birth was 7.71 million per hemisphere, a $46 \%$ decrease with respect to their littermate controls. To verify whether this result was caused by a decrease in neuron number versus a lower NeuN immunoreactivity, the total number of cresyl violet-stained cells in the cerebral cortex was counted in two animals. Total cortical cell number was estimated to be 15.7 million in the wild-type mouse and 9.94 million in the Fgf2 knockout, a 37\% decrease. A similar percentage of cortical neurons was missing in adult Fgf2-/- mice (25-48\%, depending on how the cells are identified) (Vaccarino et al., 1999a), suggesting that the cortical neuron reduction in Fgf null mutants is already present at birth. Conversely, the number of neurons contained within the caudate/ putamen, a major subdivision of the basal ganglia, was not changed in Fgf2 knockout mice (Table 4). Thus, the effects of a loss of Fgf 2 on neuronal number appear to be regionally specific. The presence of Fgfr-1 immunoreactivity in the basal PVE suggests that this receptor may play a separate role in the development of the basal ganglia independent of Fgf2.

The microscopic examination of the NeuN-stained sections revealed that the cortical cytoarchitecture of Fgf2 null mutants was markedly different than that of wild-type mice (Fig. 4a,b). In the wild-type cortex there was a variation in neuron size and density between upper and lower cortical layers. Neurons of the upper layers are smaller and more densely packed compared with layer 5 and 6 neurons, which are typically less densely aggregated, are larger on average, and frequently exhibit a pyramidal morphology (Fig. 4a, arrows). In Fgf2 knockout mice, the upper cortical layers appeared morphologically similar to wild type, but the lower cortical layers were even more sparsely packed than these layers in the wild-type mice. In addition, Fgf 2 knockouts had very few large pyramidal-shaped neurons (Fig. 4b). This 
Table 1. Cell density $\left(10^{4}\right.$ cells $/ \mathrm{mm}^{3} \pm$ SEM) in the dorsal neuroepithelium (PVE) of Fgf2 null mutant mice

\begin{tabular}{|c|c|c|c|c|c|c|}
\hline \multirow[b]{2}{*}{ Genotype } & \multicolumn{3}{|c|}{ Nondividing cells } & \multicolumn{3}{|c|}{ Dividing cells } \\
\hline & E10.5 & E11.5 & E12.5 & E10.5 & E11.5 & E12.5 \\
\hline Wild type & $84.6 \pm 5.7$ & $119 \pm 9.0$ & $85.7 \pm 27.2$ & $559 \pm 6.3$ & $842 \pm 26.5$ & $713 \pm 11.8$ \\
\hline Fgf2-/- & $116 \pm 12.2$ & $286 \pm 83.7$ & $112 \pm 13.5$ & $392 \pm 20.4$ & $747 \pm 95.1$ & $607 \pm 57.8$ \\
\hline$\%$ of wild type & 137 & 240 & 131 & 70 & 89 & 85 \\
\hline
\end{tabular}

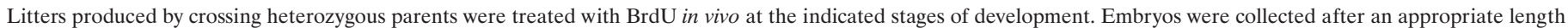

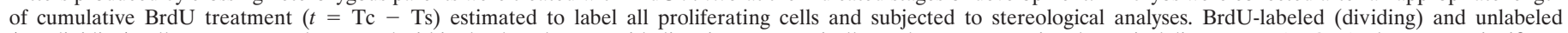

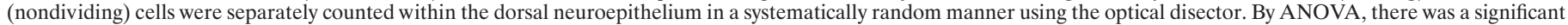

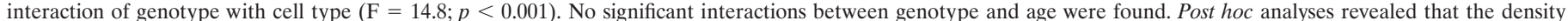

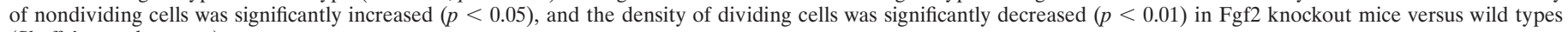
(Sheffe's post hoc tests).

Table 2. Cell number $\left(10^{4}\right.$ cells \pm SEM) in the dorsal neuroepithelium (PVE) of Fgf2 null mutant mice

\begin{tabular}{|c|c|c|c|c|c|c|}
\hline \multirow[b]{2}{*}{ Genotype } & \multicolumn{3}{|c|}{ Nondividing cells } & \multicolumn{3}{|c|}{ Dividing cells } \\
\hline & E10.5 & E11.5 & E12.5 & E10.5 & E11.5 & E12.5 \\
\hline Wild type & $9.3 \pm 2.5$ & $22.6 \pm 4.6$ & $25.3 \pm 7.1$ & $59.6 \pm 12.0$ & $157 \pm 23.5$ & $221 \pm 19.9$ \\
\hline Fgf $2-/-$ & $6.9 \pm 0.71$ & $31.8 \pm 0.4$ & $24.9 \pm 4.1$ & $24.0 \pm 4.0$ & $87.2 \pm 3.8$ & $132 \pm 9.3$ \\
\hline$\%$ of wild type & 74 & 141 & 98 & 40 & 55 & 60 \\
\hline
\end{tabular}

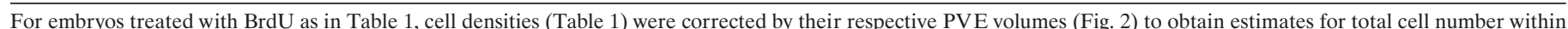

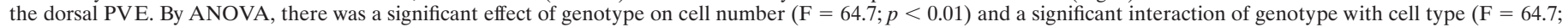

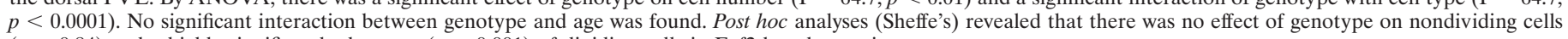
$(p=0.84)$ and a highly significantly decrease $(p<0.001)$ of dividing cells in Fgf 2 knockout mice.

phenotype was prominent in the frontal cortex, and similar results were noted, but less prominently, in the parietal cortex.

\section{The absence of Fgf2 does not affect programmed cell death (apoptosis) during corticogenesis}

One explanation for the decrease in the progenitor cell pool may be an increase in apoptosis of precursor cells caused by the lack of trophic support normally provided by the Fgf2 protein. Additionally, Fgf2 null mutant mice may fail to attain the number of cortical neurons present in wild-type mice because migrating neurons die before or shortly after reaching the cortical plate. Since it has been suggested that Fgf2 may be necessary for neuronal migration (Dono et al., 1998), one possibility is that massive neuronal apoptosis occurs in connection with defective cell migration in the IZ. To investigate these possibilities, we examined ongoing cell death in the embryonic PVE, the IZ, and the cortical plate by the TUNEL assay. Experiments were performed in sections from the brains of the same mutant and wild-type mice that were used for the estimation of morphometric parameters. Embryos were examined at E10.5, E11.5, E12.5, and E15.5. By E15.5, the earliest born neurons (layers I, VI and part of $\mathrm{V}$ ) already populate the cortical plate, and massive neuronal migration occurs in the IZ.

At E10.5-E11.5, apoptotic cells were visualized in the superficial ectoderm, mesoderm, and frontonasal mesenchime of all the

\begin{tabular}{lcccc}
\hline \multicolumn{5}{l}{ Table 3. Growth fraction ( \pm SEM) } \\
& E10.5 & E11.5 & E12.5 & E15.5 \\
\hline Wild type & $0.87 \pm 0.007$ & $0.88 \pm 0.007$ & $0.89 \pm 0.03$ & $0.91 \pm 0.02$ \\
Fgf2-/- & $0.77 \pm 0.003$ & $0.72 \pm 0.03$ & $0.84 \pm 0.02$ & $0.89 \pm 0.02$ \\
$\%$ of wild type & 89 & 83 & 94 & 98 \\
\hline
\end{tabular}

The growth fraction was estimated by calculating the proportion of BrdU-positive nuclei with respect to total nuclei for each genotype. This estimation was based on a systematic random sampling of cells within the neuroepithelium in serial sections encompassing the whole extent of the dorsal PVE. mice examined. Numerous apoptotic cells were present in the neuroepithelium in the dorsal midline (lamina terminalis) and in the prospective hippocampus (data not shown). In the dorsolateral telencephalon (the prospective cerebral cortex), however, the number of dying cells was a small percentage of the total population. The distribution of apoptotic cells confirms other results obtained with either the TUNEL technique or in situ caspase-3 activation (Thomaidou et al., 1997; Kuan et al., 1999). No difference in the number of apoptotic cells was present between Fgf2-/- mice and wild-type littermates (Fig. 5a,b). At E15.5, scattered apoptotic cells could still be visualized within the PVE (Fig. 5c, arrowhead), and again no difference was noted among control and mutant embryos. No apoptotic cells were visualized in the developing intermediate zone and cortical plate of either wild-type or Fgf2 null mutant mice (Fig. $5 c, d$ ). Conversely, numerous dying cells were present in the skin, the meninges, and the mesenchime, as well as in the endothelium lining the nose and the oral cavity (Fig. 5c,f). Thus, the TUNEL assay was sensitive enough to detect apoptotic cells, yet young neurons did not appear to die as a result of the lack of Fgf2. Note that at E15.5 there was a marked reduction in the thickness of all the layers in the emerging cortical wall in Fgf2 knockout mice (Fig. $5 c, d$ ).

\section{DISCUSSION}

These studies demonstrate that the Fgf2 gene is required for the normal proliferation of a subset of cortical progenitor cells during embryonic development and for the generation of cortical neurons during neurogenesis. We show that Fgf2 null mutant mice have a lower number of proliferative cells during early stages of corticogenesis and slower kinetics of increase in volume and cell number within the PVE. These changes result in a prominent decrease in the number of neurons within the cerebral cortex by the end of neurogenesis. Conversely, the basal ganglia are not affected by the Fgf2 null mutation, either during early embryogenesis or in the postnatal period. 
Table 4. Neuronal number (million cells \pm SEM) in the developing cortical plate of Fgf 2 null mutant mice

\begin{tabular}{lcc} 
& Cerebral cortex & Basal ganglia \\
\hline Wild type & $14.25 \pm 2.3$ & $2.4 \pm 0.45$ \\
Fgf2-/- & $7.71 \pm 0.73^{* *}$ & $2.8 \pm 0.71$ \\
$\%$ of wild type & 54 & 117
\end{tabular}

Mice ( $n=4$ wild type and 4 Fgf2 knockout) were analyzed at P1-P3. The number of postmitotic neurons was assessed within the cortical plate by stereological analyses after NeuN immunostaining. Values are for half hemisphere. By ANOVA, there was a significant effect of genotype on cell number $(\mathrm{F}=6.9 ; p<0.05)$ and a significant interaction of genotype with brain region $(\mathrm{F}=9.07 ; p<0.01)$. Post hoc analyses revealed that the number of neurons was significantly decreased in Fgf2 knockout mice versus wild types in the cerebral cortex only ( ${ }^{*} p<0.01$, Sheffe's post hoc tests). No significant difference was present between values for P1 and P3.

\section{Fgf2 expression is most prominent within the dorsal PVE and at the earliest stages of neurogenesis}

We show that the Fgf2 protein is expressed in both the cytoplasm and nuclei of cells throughout the thickness of the PVE at the beginning of neurogenesis, mirroring the distribution of Fgf2 mRNA at corresponding stages of development (Vaccarino et al., 1999a,b). The Fgf2 protein is particularly abundant within apical cells. This pattern of expression may be coupled to the cell cycle or may be caused by a paracrine uptake of Fgf2 from adjacent cells or the cerebrospinal fluid (Fig. 6). Some studies have failed to detect the Fgf2 gene product during CNS development (Eckenstein et al., 1994; Kuzis et al., 1995), which may be attributable to the transient nature of Fgf2 expression. Remarkably, the Fgf2 protein is downregulated within the PVE by midneurogenesis and is virtually absent near the end of neurogenesis. A similar downregulation exists for the Fgf2 mRNA (Vaccarino et al., 1999a). Furthermore, both Fgfr-1 message (Vaccarino et al., 1999a) and protein (this study) decline over the neurogenetic period within the PVE. The factors that drive the joint downregulation of Fgf2 and Fgfr-1 during neuronal development are currently unknown. Neuronal progenitors and stem cells require Fgf2 to self-regenerate and maintain their undifferentiated state in vitro (Ray et al., 1993; Ray and Gage, 1994; Vaccarino et al., 1995; Kalyani et al., 1997; Mayer-Proeschel et al., 1997). Hence, it is possible that the natural decline in Fgf2/Fgfr-1 expression may be permissive for the differentiation of neuronal progenitors during corticogenesis. Alternatively, this decline in Fgf2/Fgfr-1 expression may reflect a natural evolution in the relative role of molecules governing cell proliferation and fate within the PVE (Ciccolini and Svendsen, 1998; Tropepe et al., 1999). The nature of the cells adjacent to the ventricular surface that maintain high Fgf2 expression during this period is presently unknown.

\section{Fgf2 null mutant mice have fewer proliferating cells within the cortical neuroepithelium}

To determine what role, if any, Fgf2 plays in telencephalic progenitors, we analyzed the growth dynamics of the embryonic neuroepithelium in the absence of the Fgf2 gene product. We found a decrease in the size of the dorsal PVE, but not of the basal PVE, in Fgf2 knockout embryos. These data suggest that Fgf 2 is required for the normal morphogenesis of the cerebral cortex, whereas it may not be crucially involved in the development of the basal ganglia.

The decrease in volume of the dorsal PVE is attributable to a smaller number of founder cells at the start of neurogenesis (E10.5) in Fgf2 knockout embryos. This leads to a reduced expansion of the progenitor population, which is confirmed by the
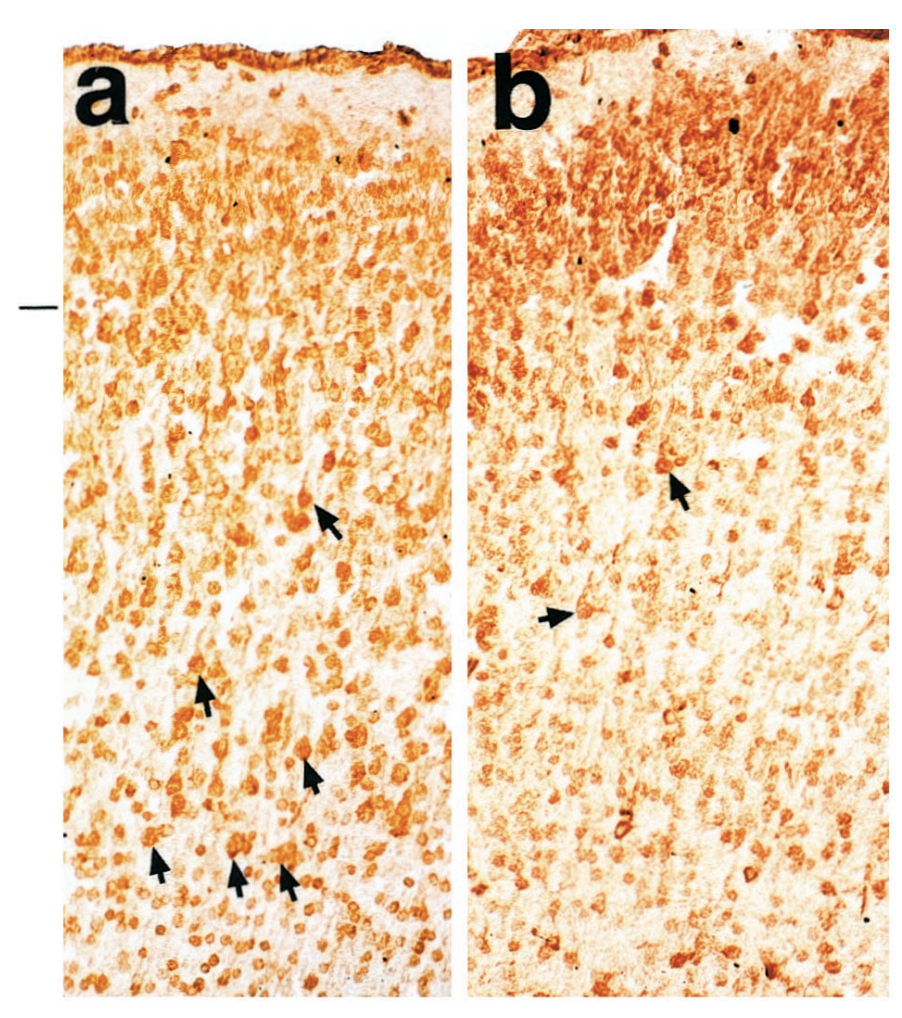

Figure 4. Cerebral cortical neurons in newborn FGF2-/- mice. Shown is NeuN immunostaining in the frontal cortex of wild-type $(a)$ and FGF2-/- mice (b) at P1. The bar at left indicates the boundary between supragranular and infragranular layers. Note the prominent nuclear staining of large, pyramidal-shaped cells in layer 5/6 (arrows) in wild-type mice that is absent in FGF2-/- mice. No difference in neuronal number is apparent in upper layers. Pial side is at the top. Scale bar, $100 \mu \mathrm{m}$.

slower accretion of cells within the PVE progenitor pool over the first few days of neurogenesis (Fig. 3). Eventually, these changes lead to a decrease in the number of cortical neurons at birth (see below). Because there are no changes in the length of the cell cycle in the dorsal PVE of Fgf2 knockout mice at E10.5 but there is a lower proportion of proliferative cells with respect to the total pool (growth fraction) (Vaccarino et al., 1999a), cortical progenitor cells may be more likely to enter a quiescent state in the absence of Fgf2.

Our data clearly indicate that only $\sim 50 \%$ of cells within the dorsal PVE require Fgf2; indeed, it has been suggested that cortical progenitors are heterogeneous with respect to their proliferative kinetics, cell fate, and sensitivity to growth factors (Acklin and van der Kooy, 1993; Vaccarino et al., 1995). Alternatively, different Fgf family members may be available to neuronal progenitors depending on local differences in the cell microenvironment.

A possible mechanism accounting for the decrease in dorsal PVE cell number is an increase in cell death. Cell death is increasingly recognized as a possible fate for proliferating neuroblasts (Morshead and van der Kooy, 1992; Blaschke et al., 1996; Blaschke et al., 1998). Hence, the observed decrease in size of the progenitor pool in the absence of Fgf2 could be attributable to Fgf2 enhancing the survival of progenitor cells. However, we were unable to find any change in the level of cell death in Fgf2 null mutant mice, in either the neuroepithelium or postmitotic layers. Although it is still possible that Fgf2 affects the survival of a small population of progenitor cells undetectable with the 


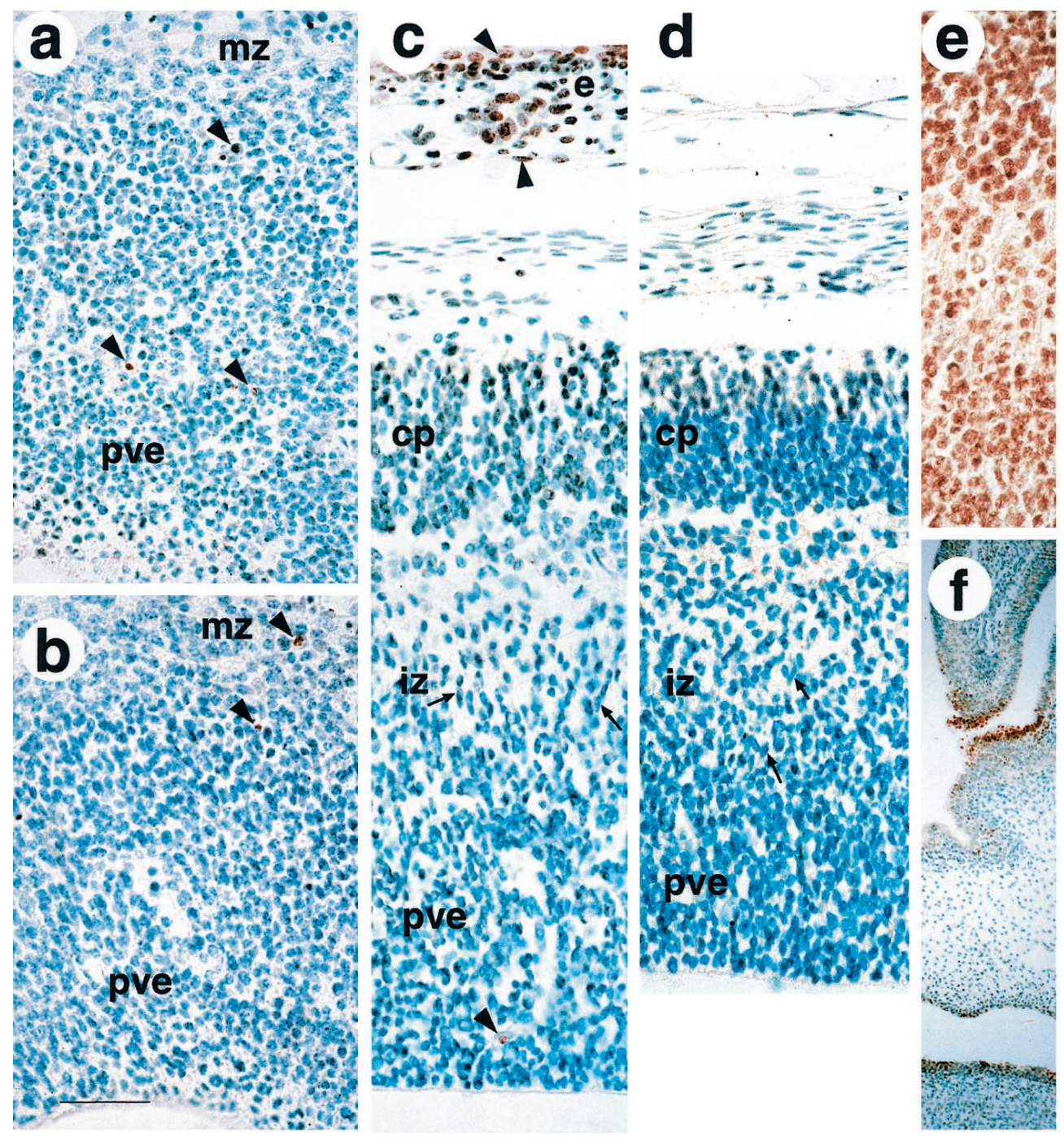

Figure 5. Apoptosis during forebrain development in wild-type and Fgf2-/mice. Shown is TUNEL assay in parasagittal sections from wild-type ( $a, c, e$, $f)$ and Fgf2-/- $(b, d)$ mice counterstained with methyl green. Apoptotic cells (brown) are indicated by arrowheads, and arrows point to migrating neurons in the intermediate zone. Age is indicated above the panels. $e$ is a positive control treated with DNase, and $f$ shows the nasal cavity with apoptotic cells at the tips of the nasal turbinates and in the endothelium of the tongue. The ventricular surface is at the bottom. $p v e$, Pseudostratified ventricular epithelium; $i z$, intermediate zone; $c p$, cortical plate; $m z$, marginal zone; $e$, epidermis. Scale bars:, $a-e, 100 \mu \mathrm{m} ; f, 200 \mu \mathrm{m}$. current techniques, the impact of such an effect for the overall phenotype is likely to be small.

\section{Fgf2 regulates the number of cortical neurons generated within the dorsal telencephalic neuroepithelium}

To determine whether the proliferative defects within the dorsal PVE decrease neurogenesis in Fgf 2 knockout mice, we estimated the total number of cerebral cortical neurons at P1, after the completion of neurogenesis. Neonatal Fgf2-/- mice had a $\sim 50 \%$ decrease in neuron number in the cortical plate compared with wild-type mice. We previously determined that Fgf2-/mice have a $25-48 \%$ decrease in the total number of neurons in the mature cerebral cortex (Vaccarino et al., 1999a). Together, these data suggest that a reduction in cortical neurons comparable to that found in the adult is already present by the end of neurogenesis in Fgf2 knockout mice and that decreased neurogenesis is the most likely explanation for the Fgf2-/- cortical phenotype. These data lead us to conclude that despite its potent survival effects in vitro (Walicke, 1988), Fgf2 is not essential for postnatal neuronal survival, at least under basal conditions. First, if Fgf2 were required to prevent neuronal death in vivo, Fgf2 null mice should display a more profound cortical neuron loss in adulthood than at birth. Second, there is actually less postnatal cell death in Fgf2 knockout mice than in wild-type mice. As NeuN-positive cells are 8.8 and 5.4 million in adult wild-type and Fgf2 knockout mice, respectively (Vaccarino et al., 1999a), the number of NeuN-positive neurons that die between birth and adulthood is $\sim 7$ million cells in wild-type mice and 2.3 million in Fgf2 knockout mice, which represent 50 and $30 \%$, respectively, of the neurons that are born. This effect may represent an indirect compensatory phenomenon for the decreased generation of cortical neurons in Fgf2 knockout mice.

Fgf2 and Egf play different roles in cortical development. There are no abnormalities in the cerebral cortex of Egfr mutant mice at birth, but cortical neurons die progressively, and the rostral portion of the cerebral cortex degenerates beginning at P4 (Sibilia and Wagner, 1995; Sibilia et al., 1998). Thus, Egfr is not required for cortical morphogenesis but is essential for neuronal survival during postnatal stages of development.

In Ffgf 2 knockout mice the proliferative population of the PVE is $40 \%$ of the wild type at the beginning of neurogenesis (E10.5). Thus, one might expect that in the absence of any compensatory phenomenon the number of neurons in the cortical plate would also be $40 \%$ of wild type. Instead, the number of cortical neurons of Fgf2-/- mice is $54 \%$ of wild type at the completion of neurogenesis, $30 \%$ larger than expected. These 
data suggest that some compensatory mechanism has partially corrected for what might otherwise have been a much larger difference in size. We observed (Table 2) that the number of proliferative cells in the dorsal PVE is $40 \%$ of wild type at E10.5, but rises to 55 and $60 \%$ of wild type at E11.5 and E12.5, respectively. In the absence of any compensatory adjustment, we would have expected that at E12.5 the number of proliferative cells would have remained $40 \%$ of wild type, thus the rise to $60 \%$ of wild type is $50 \%$ larger than expected. This indicates that between E10.5 and E12.5 more cells remain in the proliferative population to compensate for the initial loss in the progenitor pool and that the abnormalities in cell proliferation of Fgf2 null mutant mice are partially compensated for between E10.5 and E12.5. In the wild-type mouse, this $48 \mathrm{hr}$ period is enough for five cell cycles (Takahashi et al., 1999). Because the kinetics of the cell cycle and the proportion of cell death do not appear to be changed in Fgf2 null mutants (Vaccarino et al., 1999a; and this study), we suggest that the mechanism of this partial compensation is a relative decrease in the rate of ascent of the $Q$ fraction for the progenitors that remain in the mutant PVE. The molecular events that may account for this change include the emergence of progenitor cells responding to other growth factors, including other Fgfs, or a change in level or responsiveness to cell cycle inhibitors. Other compensatory events enacted by the Fgf2-/- mutation may be represented by a prolongation of the time of neurogenesis and cell migration (see below). In conclusion, our results suggest that the processes controlling neurogenesis possess some degree of inherent flexibility, where the removal of one regulatory molecule may trigger counterbalancing influences that serve to maintain proliferation within the embryonic neuroepithelium.

In addition to a change in the dynamics of cell proliferation, a partial compensation for the cortical cell loss in Fgf2 null mutant mice is likely to be provided by the migration of another class of neurons from the basal ganglia. Cortical interneurons originate from precursors within the ganglionic eminence and migrate to the cerebral cortex as early as E12.5. During their migration they navigate through the intermediate zone or the marginal layer (Anderson et al., 1997a; Pearlman, 1998; Lavdas et al., 1999). Because Fgf2 is not required for neurogenesis within the basal ganglia, interneuron migration to the cortex should be preserved in Fgf2-/- mice. Confirming this suggestion, we observed that large, pyramidal-type neurons were most notably missing in Fgf2 knockout mice, whereas small neurons were preserved (Fig. 4). GABAergic interneurons and glutamatergic projection neurons are one-third and two-thirds, respectively, of all cortical neurons (Jones and Peters, 1984; Vaccarino et al., 1999a). Assuming that most cortical GABAergic cells are contributed from the embryonic basal ganglia, we estimate that we would have $\sim 14.25-$ $4.25=9.5$ million projection neurons in wild types and 7.71$4.25=2.96$ million projection in Fgf2 knockout at P1. Thus, under the above assumptions, the actual depletion of cortical projection neurons contributed by the dorsal PVE in Fgf2 null mutant mice would be in the range of $70 \%$.

Adult Fgf $2-/-$ mice have a $40 \%$ decrease in the number of glial cells. The generation of glial cells begins in the later portion of neurogenesis in the SPP and continues in the postnatal period. Because the SPP is seeded from progenitors originating from the PVE, there are likely to be abnormalities in the SPP as well in Fgf2-/- mutants.

There are examples of gene knockouts where the degree (Sibilia and Wagner, 1995; Bonyadi et al., 1997; Suda et al., 1997;

\section{A}

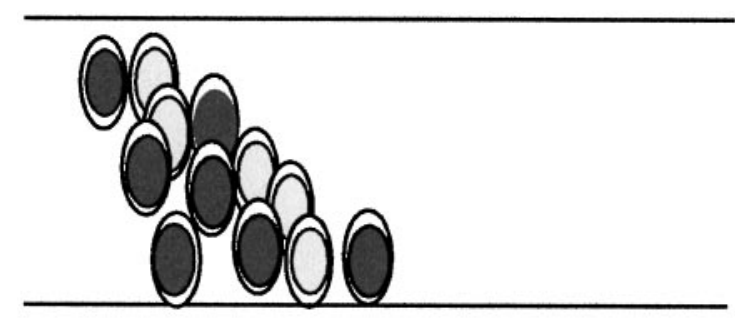

B

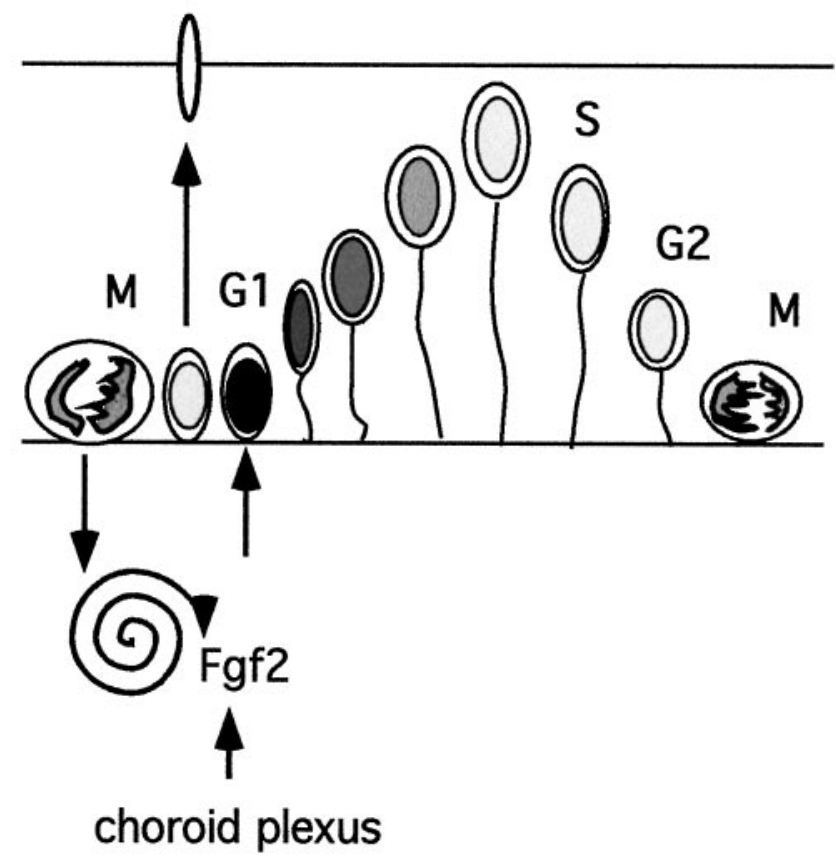

Figure 6. Model of the possible relationships between Fgf2 availability and cell cycle events. $A$, Salt-and-pepper appearance of Fgf2 mRNA in the early PVE (Vaccarino et al., 1999a), suggesting that cell-to-cell variability in internal sources of Fgf2 may represent a primary factor governing Fgf2 exposure within these cells and their neighbors. $B$, At later stages of development, Fgf2 is downregulated within the PVE except for the cells close to the apical surface. The interkinetic nuclear movement coupled to the cell cycle is shown in relation to the hypothesized action of Fgf2. In a subset of progenitor cells, Fgf2 is necessary in early G1 to promote commitment to a subsequent cell cycle (DeHamer et al., 1994). During early G1, cells are also close to the ventricular surface, which could be a source of Fgf2 protein. Fgf2 may be released into the CSF by PVE cells or by cells of the choroid plexus, which contain high amounts of Fgf2. The increased nuclear shading represents the association of Fgf ligands with the nucleus, also occurring during the $\mathrm{G} 1$ phase (Zhan et al., 1993; Prudovsky et al., 1994).

Nakao et al., 1998) or presence (LeCouter et al., 1998; McNamara et al., 1998) of phenotypic alterations depends on the genetic background. This variable penetrance may be attributable to modifier genes that have epistatic relationships with the mutated locus, or to genes linked to the targeted locus (Gerlai, 1996). 
To minimize the likelihood that differences detected among Fgf $2+/+$ and Fgf2-/ - are attributable to the effect of genetic variation, we have quantitatively analyzed a large number of animals. If the Fgf2-/- phenotype were caused by genetic variation, statistical significance should have decreased with an increase in the number of animals analyzed. Furthermore, the cerebral cortical abnormalities are not restricted to the Fgf2 knockout strain used in our studies (129Sv: Black Swiss) but also involve the 129Sv:C57BL/6strain (Ortega et al., 1998) (our unpublished observations). However, because both 129Sv: Black Swiss and 129Sv:C57BL/6 are mixed strains containing portions of the $125 \mathrm{~Sv}$ genome, it will be important to transfer the Fgf2 mutation in a homogeneous genetic background to fully understand the implications of Fgf2 for cortical development.

\section{Fgf2 and cell differentiation}

Previous in vitro data suggested that Fgf2 induces progenitor cells to undergo additional mitoses (Bogler et al., 1990; McKinnon et al., 1990; Kilpatrick and Bartlett, 1993; DeHamer et al., 1994; Bouvier and Mytilineou, 1995; Vaccarino et al., 1995; Cavanagh et al., 1997). Because cells normally differentiate after they have undergone their last mitotic cycle, Fgf2 may also influence the timing of cell differentiation. The present work in vivo shows that this action may apply to a subset of progenitor cells, representing $\sim 50 \%$ of the cortical progenitor cell pool at E10.5. We propose that high levels of Fgfs would initially inhibit cell differentiation, allowing the expansion of this particular subset of neuronal progenitors. The decline in Fgf expression indeed parallels the rise in the $\mathrm{Q}$ fraction, which is the fraction of cells that exit the cycle during neurogenesis (Takahashi et al., 1996).

In primary neuronal cultures, Fgf2 has been reported to increase neuronal differentiation (Murphy et al., 1990; VicarioAbejon et al., 1995). To our knowledge, there is no direct evidence for a specific effect of Fgf2 on the process of cell differentiation. If Fgf2 normally enhances neuronal differentiation, we would have predicted an increase in progenitor cell number in Fgf2 knockout mice. In some cases, previous exposure to Fgf2 may be required for optimal response to differentiationinducing factors in vitro (Murphy et al., 1994; Pincus et al., 1998). These effects on neuron number can be explained if Fgf2 were adding cell cycles within a committed neurogenic program. The number of cell cycles for a given progenitor lineage, which we may call the lineage "age," is coded within the PVE by the length of the G1 phase of the cell cycle (Miyama et al., 1997). The age of lineages influences their competence to differentiate into specific cell fates (McConnell and Kaznowski, 1991; Frantz and McConnell, 1996). One determinant of age of lineages may be Fgf2. Exposure to Fgf2 is conditioned by Fgf2 synthesis and the possible availability of Fgf2 through paracrine cell-to-cell signaling or the CSF (for a model, see Fig. 6). We have previously shown that Fgf2 uptake from the CSF via intraventricular microinjection is a potent mitogenic stimulus for cortical progenitor cells (Vaccarino et al., 1999a). Fgf uptake and binding by apical cells may result in the translocation of ligand/receptor complexes to a nuclear locale, which has been shown to be necessary for the cell cycle reentry (Zhan et al., 1993; Prudovsky et al., 1994). During earlier development, the more widespread availability of Fgf2, synthesized within the entire depth of the PVE, would not restrict Fgf2 availability to apical cells.

\section{Conclusion}

In the absence of Fgf2, mice lack a substantial portion of cortical neurons, most likely representing projection neurons. Although the transmitter specificity of these cortical cells remains to be determined, these mice are likely to have alterations in cortical circuitry and may be cognitively impaired. Functional and behavioral examination of these mice may shed light on the correlation between cerebral cortical structure and aspects of cognition.

\section{REFERENCES}

Acklin SE, van der Kooy D (1993) Clonal heterogeneity in the germinal zone of the developing rat telencephalon. Development 118:175-192.

Anderson SA, Eisenstat DD, Shi L, Rubenstein JL (1997a) Interneuron migration from basal forebrain to neocortex: dependence on Dlx genes. Science 278:474-476.

Anderson SA, Qiu M, Bulfone A, Eisenstat DD, Meneses J, Pedersen R, Rubenstein JLR (1997b) Mutations of the homeobox genes $D l x-1$ and $D l x-2$ disrupt the striatal subventricular zone and differentiation of late born striatal neurons. Neuron 19:1-20.

Bayer SA, Altman J (1991) Neocortical development. New York: Raven.

Blaschke AJ, Staley K, Chun J (1996) Widespread programmed cell death in proliferative and postmitotic regions of the fetal cerebral cortex. Development 122:1165-1174.

Blaschke AJ, Weiner JA, Chun J (1998) Programmed cell death is a universal feature of embryonic and postnatal neuroproliferative regions throughout the central nervous system. J Comp Neurol 396:39-50.

Bogler O, Wren D, Barnett SC, Land H, Noble M (1990) Cooperation between two growth factors promotes extended self-renewal and inhibits differentiation of oligodendrocyte-type- 2 astrocyte $(\mathrm{O}-2 \mathrm{~A})$ progenitor cells. Proc Natl Acad Sci USA 87:6368-6372.

Bonyadi M, Rusholme SA, Cousins FM, Su HC, Biron CA, Farrall M, Akhurst RJ (1997) Mapping of a major genetic modifier of embryonic lethality in TGF beta 1 knockout mice. Nat Genet 15:207-211.

Bouvier MM, Mytilineou C (1995) Basic fibroblast growth factor increases division and delays differentiation of dopamine precursors in vitro. J Neurosci 15:7141-7149.

Brown NA (1990) Postimplantation mammalian embryos. A practical approach. Oxford: IRL.

Cavanagh JFR, Mione MC, Pappas IS, Parnavelas JG (1997) Basic fibroblast growth factor prolongs the proliferation of rat cortical progenitor cells in vitro without altering their cell cycle parameters. Cereb Cortex 7:293-302.

Caviness VS, Takahashi T, Nowakowski RS (1995) Numbers, time and neocortical neurogenesis: a general developmental and evolutionary model. Trends Neurosci 18:379-383.

Ciccolini F, Svendsen CN (1998) Fibroblast growth factor 2 (FGF-2) promotes acquisition of epidermal growth factor (EGF) responsiveness in mouse striatal precursor cells: identification of neural precursors responding to both EGF and FGF-2. J Neurosci 18:7869-7880.

Craig CG, Tropepe V, Morshead CM, Reynolds BA, Weiss S, van der Kooy D (1996) In vivo growth factor expansion of endogenous subependymal neural precursor cell populations in the adult mouse brain. J Neurosci 16:2649-2658.

Crossley PH, Martinez S, Martin GR (1996) Midbrain development induced by FGF8 in the chick embryo. Nature 380:66-68.

de Carlos JA, Lopez-Mascaraque L, Valverde F (1996) Dynamics of cell migration from the lateral ganglionic eminence in the rat. J Neurosci 16:6146-6156.

DeHamer MK, Guevara JL, Hannon K, Olwin BB, Calof AL (1994) Genesis of olfactory receptor neurons in vitro: regulation of progenitor cell divisions by fibroblast growth factor. Neuron 13:1083-1097.

Deng C, Wynshaw-Boris A, Zhou F, Kuo A, Leder P (1996) Fibroblast growth factor receptor 3 is a negative regulator of bone growth. Cell 84:911-921.

Dono R, Texido G, Dussel R, Ehmke H, Zeller R (1998) Impaired cerebral cortex development and blood pressure regulation in FGF-2deficient mice. EMBO J 17:4213-4225.

Drago J, Murphy M, Carroll SM, Harvey RP, Bartlett PF (1991) Fibroblast growth factor-mediated proliferation of central nervous system precursors depends on endogenous production of insulin-like growth factor I. Proc Natl Acad Sci USA 88:2199-2203.

Eckenstein FP, Kuzis K, Nishi R, Woodward WR, Meshul C, Sherman L, Ciment G (1994) Cellular distribution, subcellular localization and possible functions of basic and acidic fibroblast growth factors. Biochem Pharmacol 47:103-110.

Ernfors P, Lonnerberg P, Ayer LLC, Persson H (1990) Developmental 
and regional expression of basic fibroblast growth factor mRNA in the rat central nervous system. J Neurosci Res 27:10-15.

Frantz GD, McConnell SK (1996) Restriction of late cerebral cortical progenitors to an upper-layer fate. Neuron 17:55-61.

Gavrieli Y, Sherman Y, Ben-Sasson SA (1992) Identification of programmed cell death in situ via specific labelling of nuclear fragmentation. J Cell Biol 119:493-501.

Gensburger C, Labourdette G, Sensenbrenner M (1987) Brain basic fibroblast growth factor stimulates the proliferation of rat neuronal precursor cells in vitro. FEBS Lett 217:1-5.

Gerlai R (1996) Gene-targeting studies of mammalian behavior: is the mutation or the background genotype? Trends Neurosci 19:177-181.

Giordano S, Sherman L, Morrison R (1991) Multiple molecular weight forms of basic fibroblast growth factor are developmentally regulated in the rat central nervous system. Ann NY Acad Sci 638:420-423.

Gonzalez AM, Buscaglia M, Ong M, Baird A (1990) Distribution of basic fibroblast growth factor in the 18-day rat fetus. J Cell Biol 110:753-765.

Gonzalez AM, Berry M, Maher PA, Logan A, Baird A (1995) A comprehensive analysis of the distribution of FGF-2 and FGF-1 in the rat brain. Brain Res 701:201-226.

Gundersen HJ, Bagger P, Bendtsen TF, Evans SM, Korbo L, Marcussen N, Moller A, Nielsen K, Nyengaard JR, Pakkenberg B (1988) The new stereological tools: disector, fractionator, nucleator, and point sampled intercepts and their use in pathological research and diagnosis. APMIS 96:857-881.

Haydar TF, Nowakowski RS, Yarowsky PJ, Krueger BK (2000) Role of founder cell deficit and delayed neuronogenesis in microcephaly of the trisomy 16 mouse. J Neurosci, in press.

Jones EG, Peters A (1984) Cerebral cortex. Cellular components of the cerebral cortex. New York: Plenum.

Kalyani A, Hobson K, Rao MS (1997) Neuroepithelial stem cells from the embryonic spinal cord: isolation, characterization, and clonal analysis. Dev Biol 186:202-223.

Kilpatrick TJ, Bartlett PF (1993) Cloning and growth of multipotential neural precursors: requirements for proliferation and differentiation. Neuron 10:255-265.

Kuan C-Y, Yang DD, Samanta Roy DR, Davis RJ, Rakic P, Flavell RA (1999) The Jnk1 and Jnk2 protein kinases are required for regional specific apoptosis during early brain development. Neuron 22:667-676.

Kuhn HG, Winkler J, Kempermann G, Thal L, Gage FH (1997) Epidermal growth factor and fibroblast growth factor-2 have different effects on neural progenitors in the adult rat brain. J Neurosci 17:5820-5829.

Kuzis K, Reed S, Cherry NJ, Woodward WR, Eckenstein FP (1995) Developmental time course of acidic and basic fibroblast growth factors expression in distinct cellular populations of the rat central nervous system. J Comp Neurol 358:142-153.

Lavdas AA, Grigoriu M, Pachnis V, Parnavelas JG (1999) The medial ganglionic eminence gives rise to a population of early neurons in the developing cerebral cortex. J Neurosci 19:7881-7888.

LeCouter JE, Kablar B, Whyte PFM, Ying C, Rudnicki MA (1998) Strain-dependent embryonic lethality in mice lacking the retinoblastoma-related p130 gene. Development 125:4669-4679.

Martinez S, Crossley PH, Cobos I, Rubenstein JLR, Martin GR (1999) FGF8 induces formation of an ectopic isthmic organizer and isthmocerebellar development via a repressive effect on Otx2 expression. Development 126:1189-1200.

Mayer-Proeschel M, Kalyani AJ, Mujtaba T, Rao MS (1997) Isolation of lineage-restricted neuronal precursors from multipotent neuroepithelial cells. Neuron 19:773-785.

McConnell SK, Kaznowski CE (1991) Cell cycle dependence of laminar determination in developing neocortex. Science 254:282-285.

McKinnon RD, Matsui T, Dubois-Dalq M, Aaronson SA (1990) FGF modulates the PDGF-driven pathway of oligodendrocyte development. Neuron 5:603-614.

McNamara RK, Stumpo DJ, Morel LM, Lewis MH, Wakeland EK, PJ Blackshear PJ, Lenox RH (1998) Effect of reduced myristoylated alanine-rich $\mathrm{C}$ kinase substrate expression on hippocampal mossy fiber development and spatial learning in mutant mice: transgenic rescue and interactions with gene background. Proc Natl Acad Sci USA 95:14517-14522.

Miyama S, Takahashi T, Nowakowski RS, Caviness VS (1997) A gradient in the duration of the G1 phase in the murine neocortical proliferative epithelium. Cereb Cortex 7:678-689.
Morshead CM, van der Kooy D (1992) Postmitotic death is the fate of constitutively proliferating cells in the subependymal layer of the adult mouse brain. J Neurosci 12:249-256.

Murphy M, Drago J, Bartlett PF (1990) Fibroblast growth factor stimulates the proliferation and differentiation of neural precursor cells in vitro. J Neurosci Res 25:463-475.

Murphy M, Reid K, Ford M, Furness JB, Bartlett PF (1994) FGF2 regulates proliferation of neuronal crest cells, with subsequent neuronal differentiation regulated by LIF or related factors. Development 120:3519-3528.

Nakao N, Hiraiwa N, Yoshiki A, Ike F, Kusakabe M (1998) Tenascin-C promotes healing of Habu-snake venom-induced glomerulonephritis: studies in knockout congenic mice and in culture. Am J Pathol 152:1237-1245.

Nurcombe V, Ford MD, Wildschut JA, Bartlett PF (1993) Developmental regulation of neural response to FGF-1 and FGF-2 by heparan sulfate proteoglycan. Science 260:103-106.

Ortega S, Ittmann M, Tsang SH, Ehrich M, Basilico C (1998) Neuronal defects and delayed wound healing in mice lacking fibroblast growth factor 2. Proc Natl Acad Sci USA 95:5672-5677.

Partanen J, Schwartz L, Rossant J (1998) Opposite phenotypes of hypomorphic and Y766 phosphorylation site mutations reveal a function for Fgfr1 in anteroposterior patterning of mouse mesoderm. Genes Dev 12:2332-2344.

Pearlman AL (1998) New directions for neuronal migration. Curr Opin Neurobiol 8:45-54.

Pincus DW, Keyoung HM, Harrison-Restelli C, Goodman RR, Frazer RAR, Edgar M, Sakakibara S, Okano H, Nedergaard M, Goldman SA (1998) Fibroblast growth factor-2 brain-derived neurotrophic factorassociated maturation of new neurons generated from adult human subeperdimal cells. Ann Neurol 43:576-585.

Powell PP, Finklestein SP, Dionne CA, Jaye M, Klagsbrun M (1991) Temporal, differential and regional expression of mRNA for basic fibroblast growth factor in the developing and adult rat brain. Brain Res Mol Brain Res 11:71-77.

Prudovsky I, Savion N, Zhan X, Friesel R, Xu J, Hou J, McKeehan WL, Maciag T (1994) Intact and functional fibroblast growth factor (FGF) receptor-1 trafficks near the nucleus in response to FGF-1. J Biol Chem 269:31720-31724.

Ray J, Gage FH (1994) Spinal cord neuroblasts proliferate in response to basic fibroblast growth factor. J Neurosci 14:3548-3564.

Ray J, Peterson DA, Schinstine M, Gage FH (1993) Proliferation, differentiation, and long-term culture of primary hippocampal neurons. Proc Natl Acad Sci USA 90:3602-3606.

Represa J, Leon Y, Miner C, Giraldez F (1991) The int-2 protooncogene is responsible for induction of the inner ear. Nature 353:561-563.

Reznikov K, van der Kooy D (1995) Variability and partial synchrony of the cell cycle in the germinal zone of the early embryonic cerebral cortex. J Comp Neurol 360:536-554.

Shimamura K, Rubenstein JLR (1997) Inductive interactions direct early regionalization of the mouse forebrain. Development 124:2709-2718.

Sibilia M, Wagner EF (1995) Strain-dependent epithelial defects in mice lacking the EGF receptor. Science 269:234-238.

Sibilia M, Steinbach JP, Stingl L, Aguzzi A, Wagner EF (1998) A strainindependent postnatal neurodegeneration in mice lacking the EGF receptor. EMBO J 17:719-731.

Suda Y, Matsuo I, Aizawa S (1997) Cooperation between Otx1 and Otx2 genes in developmental patterning of the rostral brain. Mech Dev 69:125-141.

Takahashi T, Nowakowski RS, Caviness Jr VS (1993) Cell cycle parameters and patterns of nuclear movement in the neocortical proliferative zone of the fetal mouse. J Neurosci 13:820-833.

Takahashi T, Nowakowski RS, Caviness Jr VS (1995) The cell cycle of the pseudostratified ventricular epithelium of the embryonic murine cerebral wall. J Neurosci 15:6046-6057.

Takahashi T, Nowakowski RS, Caviness Jr VS (1996) The leaving or Q fraction of the murine cerebral proliferative epithelium: a general model of neocortical neuronogenesis. J Neurosci 16:6183-6196.

Takahashi T, Goto T, Miyama S, Nowakowski RS, Caviness Jr VS (1999) Sequence of neuron origin and neocortical laminar fate: relation to cell cycle of origin in the developing murine cerebral wall. J Neurosci 19:10357-10371.

Tan SS, Kalloniatis M, Sturm K, Tam PPL, Reese BE, Faulkner-Jones B 
(1998) Separate progenitors for radial and tangential cell dispersion during development of the cerebral cortex. Neuron 21:295-304.

Thomaidou D, Mione MC, Cavanagh JFR, Parnavelas JG (1997) Apoptosis and its relation to the cell cycle in the developing cerebral cortex. J Neurosci 17:1075-1085.

Tropepe V, Sibilia M, Ciruna BG, Rossant J, Wagner EF, van der Kooy D (1999) Distinct neural stem cells proliferate in response to EGF and FGF in developing mouse telencephalon. Dev Biol 208:166-188.

Vaccarino FM, Schwartz ML, Hartigan D, Leckman JF (1995) Effect of basic fibroblast growth factor on the genesis of excitatory and inhibitory neurons in primary cultures of cells from the mammalian telencephalon. Cereb Cortex 1:64-78.

Vaccarino FM, Schwartz ML, Raballo R, Nilsen J, Rhee J, Zhou M, Doetschman T, Coffin JD, Wyland JJ, Hung Y-TE (1999a) Changes in cerebral cortex size are governed by fibroblast growth factor during embryogenesis. Nat Neurosci 2:246-253.

Vaccarino FM, Schwartz ML, Raballo R, Rhee J, Lyn-Cook R (1999b) Fibroblast growth factor signaling regulates growth and morphogenesis at multiple steps during brain development. In: Current topics in developmental biology (Pedersen RA, Shatten G, eds), pp 179-200. San Diego: Academic.

Vescovi AL, Reynolds BA, Fraser DD, Weiss S (1993) bFGF regulates the proliferative fate of unipotent (neuronal) and bipotent (neuronal/ astroglial) EGF-generated CNS progenitor cells. Neuron 11:951-966.

Vicario-Abejon C, Johe KK, Hazel TG, Collazo D, McKay RDG (1995) Functions of basic fibroblast growth factor and neurotrophins in the differentiation of hippocampal neurons. Neuron 15:105-114.

Walicke PA (1988) Basic and acidic fibroblast growth factors have tro- phic effects on neurons from multiple CNS regions. J Neurosci 8:2618-2627.

Weinstein M, Xu X, Ohyama K, Deng C-X (1998) FGFR-3 and FGFR-4 function cooperatively to direct alveogenesis in the murine lung. Development 125:3615-3623.

Weise B, Janet T, Grothe C (1993) Localization of bFGF and FGFreceptor in the developing nervous system of the embryonic and newborn rat. J Neurosci Res 34:442-453.

West MJ (1993) New stereological methods for counting neurons. Neurobiol Aging 14:275-285.

West MJ, Slomianka L, Gundersen HJ (1991) Unbiased stereological estimation of the total number of neurons in the subdivisions of the rat hippocampus using the optical fractionator. Anat Rec 231:482-497.

Woodward WR, Nishi R, Meshul CK, Williams TE, Coulombe M, Eckenstein FP (1992) Nuclear and cytoplasmic localization of basic fibroblast growth factor in astrocytes and CA2 hippocampal neurons. J Neurosci 12:142-152.

Yamaguchi TP, Harpal K, Henkemeyer M, Rossant J (1994) fgfr-1 is required for embryonic growth and mesodermal patterning during mouse gastrulation. Genes Dev 8:3032-3044.

Zhan X, Hu X, Friesel R, Maciag T (1993) Long term growth factor exposure and differential tyrosine phosphorylation are required for DNA synthesis in Balb/c3T3 cells. J Biol Chem 268:9611-9620.

Zhou M, Sutliff RL, Paul RJ, Lorenz JN, Hoying JB, Haudenschild CC, Yin M, Coffin JD, Kong L, Kranias EG, Luo W, Boivin GP, Duffy JJ, Pawlowski SA, Doetschman T (1998) Fibroblast growth factor 2 controls vascular tone. Nat Med 4:201-207. 